\title{
A comparison of four systems of group mating for avoiding inbreeding
}

\author{
T Nomura, K Yonezawa \\ Faculty of Engineering, Kyoto Sangyo University, Kyoto 603, Japan
}

(Received 22 February 1995; accepted 15 November 1995)

\begin{abstract}
Summary - Circular group mating has been considered one of the most efficient systems for avoiding inbreeding. In this system, a population is conserved in a number of separate groups and males are transferred between neighbouring groups in a circular way. As alternatives, some other mating systems such as Falconer's system, HAN-rotational system and Cockerham's system have been proposed. These systems as a whole are called cyclical systems, since the male transfer between groups changes in a cyclical pattern. In the present study, circular group mating and the three cyclical systems were compared with respect to the progress of inbreeding in early and advanced generations after initiation. It was derived that the cyclical systems gave lower inbreeding coefficients than circular group mating in early and not much advanced generations. Circular group mating gave slightly lower inbreeding after generations more advanced than 100, when the inbreeding coefficient became as high as or higher than $60 \%$. Considering that it is primarily inbreeding in early generations that determines the persistence of a population, it is concluded that cyclical systems have a wider application than circular group mating. Inbreeding in the cyclical systems increased in oscillating patterns, with different amplitudes but with essentially the same trend. Among the three cyclical systems, Cockerham's system for an even number of groups and the HAN-rotational system for an odd number are advisable, since they exhibited the smallest amplitudes of oscillation.
\end{abstract}

inbreeding avoidance / inbreeding coefficient / group mating / conservation of animal population / effective population size

Résumé - Une comparaison de quatre systèmes d'accouplements par groupe pour éviter la consanguinité. Un régime d'accouplement par groupe de type circulaire est considéré comme l'un des systèmes les plus efficaces pour éviter la consanguinité. Dans ce système, la population est entretenue en groupes séparés et les mâles sont transférés de leur groupe au groupe voisin d'ane manière circulaire. D'autres systèmes, tels que le système de Falconer, le système rotatif de HAN et le système de Cockerham, ont été proposés par ailleurs. Ces derniers sont regroupés sous l'appellation de systèmes cycliques, puisque le transfert des mâles d'un groupe à l'autre obéit à un rythme cyclique. Dans cette étude, on compare le système circulaire aux trois systèmes cycliques du point de vue de l'augmentation de la consanguinité au cours des premières générations et au bout d'un nombre très élevé de générations. On montre que les systèmes cycliques 
entrâ̂nent une consanguinité moindre que le système circulaire au cours des premières générations et tant que le nombre de générations reste faible. Le système circulaire donne une consanguinité légèrement plus faible à partir de la $100^{e}$ génération, stade auquel le coefficient de consanguinité atteint ou dépasse $60 \%$. Si on considère que la consanguinité dans les premières générations est le facteur déterminant de persistance d'une population, on peut conclure que les systèmes cycliques sont à recommander de préférence $\grave{a}$ un régime d'accouplement de type circulaire. La consanguinité dans les systèmes cycliques s'accrôt selon des rythmes oscillatoires d'amplitude variable, mais autour de moyennes très peu différentes. Parmi les trois systèmes cycliques, on peut recommander le système de Cockerham pour des nombres pairs de groupes et le système rotatif de HAN pour des nombres impairs, qui sont ceux qui montrent les plus faibles amplitudes d'oscillation.

évitement de la consanguinité / coefficient de consanguinité / accouplement par groupe / conservation animale / effectif génétique

\section{INTRODUCTION}

The number of individuals maintainable in most conservation programmes of animals is quite restricted due to financial and facility limitations. In such a situation, inbreeding is expected to seriously harm the viability of populations, and thus the development of strategies for minimizing the advance of inbreeding is one of the most important problems to be solved. Circular group mating, sometimes called a rotational mating plan, is one of the systems proposed for avoiding inbreeding (Yamada, 1980; Maijala et al, 1984; Alderson, 1990a, b, 1992). In this mating system, a population is subdivided into a number of groups and males are transferred between neighbouring groups in a circular way. This system has been adopted in several conservation programmes of rare livestock breeds (Alderson, 1990a, b, 1992; Bodo, 1990).

The theoretical basis of circular group mating was established by Kimura and Crow (1963). In their theory, the rate of inbreeding in sufficiently advanced generations after initiation was shown to be smaller with circular group mating than with random mating. This ultimate rate of inbreeding, however, is not the only criterion for measuring practical use. Mating systems which reduce the ultimate rate of inbreeding tend to inflate inbreeding in early generations after initiation (Robertson, 1964). If circular group mating causes a rapid increase of inbreeding in early or initial generations, its application should be limited.

Besides circular group mating, some other systems of male exchange, such as Poiley's system (Poiley, 1960), Falconer's system (Falconer, 1967), Falconer's maximum avoidance system (Falconer, 1967), the HAN-rotational system (Rapp, 1972) and a series of Cockerham's systems (Cockerham, 1970), have been proposed. These systems as a whole are called cyclical systems in the sense that the pattern of male exchange between groups changes cyclically (Rochambeau and Chevalet, 1982). Assuming a simple model of each group consisting of only one male and one female, Rapp (1972) computed the progress of inbreeding in the initial ten generations for the first four of the systems mentioned above, leading to the conclusion that the HAN-rotational system gave the smallest rate of inbreeding. 
The four cyclical systems were compared also by Eggenberger (1973) with respect to genetic differentiation among groups in various combinations of population size and number of groups. He showed that, while there are only small differences among the four systems in the initial 20 generations, Poiley's system ultimately caused a larger genetic differentiation among groups. Matheron and Chevalet (1977) studied inbreeding in a simulated population maintained with a system called the third degree cyclical system of Cockerham. They found that by this system the inbreeding coefficient in the first ten generations was lowered by $3 \%$ compared to a random mating system. Rochambeau and Chevalet (1985) investigated some particular types of cyclical system, some of which belong to the HAN-rotational system, and showed that the cyclical system for some numbers of groups causes lower inbreeding than circular group mating in the initial 20 years.

A comparison of various types of cyclical systems with circular group mating is important for choosing an optimal mating system but remains to be investigated more systematically. In this paper, three cyclical systems (ie, Falconer's, HANrotational, and Cockerham's), in which the rule of male transfer is explicitly defined, will be compared with circular group mating taking account of the progress of inbreeding in both early and advanced generations. Based on this, optimal mating systems for animal conservation will be discussed.

\section{MODEL AND METHOD}

A population which is composed of $m$ groups with $N_{\mathrm{m}}$ males and $N_{\mathrm{f}}$ females in each is considered. The total numbers of males and females in this populations are then $N_{\mathrm{M}}=m N_{\mathrm{m}}$ and $N_{\mathrm{F}}=m N_{\mathrm{f}}$ respectively. Mating within groups is assumed to be random with random distribution of progeny sizes of male and female parents, so that the effective size $\left(N_{\mathrm{e}}\right)$ of a group is $4 N_{\mathrm{m}} N_{\mathrm{f}} /\left(N_{\mathrm{m}}+N_{\mathrm{f}}\right)$.

Circular group mating and three cyclical systems, ie, Falconer's system, the HAN-rotational system, and Cockerham's system, are investigated. Another system, maximum avoidance system of group mating (Falconer, 1967), is not investigated, because in this system males are exchanged among groups in the same way as in Wright's system of maximum avoidance of inbreeding (Wright, 1921). Application of this system is limited to cases where the number of groups equals an integral power of 2 , and the inbreeding coefficient under this mating system increases at the same rate as in Cockerham's system. Poiley's system, although it was proposed earlier than the other cyclical systems, is not investigated either. In Poiley's idea, the rule of male transfer was not consistently defined; different rules seem to be used with different numbers of groups. Also, as pointed out by Rapp (1972), the inbreeding coefficient under this system converges to different values in different groups, meaning that the progress of inbreeding cannot be formulated by a single recurrence equation.

In circular group mating, all males in a group are transferred to a neighbouring group every generation. Figure 1(a) shows a case where the population is composed of four groups. In the three cyclical systems, all males in group $i(=1,2, \ldots, m)$ in generation $t\left(=1,2, \ldots, t_{\mathrm{c}}\right)$ are transferred to group $d(i, t)$, a function defined below. This male transfer pattern is repeated with a cycle of $t_{\mathrm{c}}$ generations. 
In Falconer's system, $t_{\mathrm{c}}$ and $d(i, t)$ are given as

$$
t_{\mathrm{c}}=m-1,
$$

and

$$
d(i, t)= \begin{cases}i+t & \text { for } i+t \leqslant m \\ i+t-m & \text { for } i+t>m .\end{cases}
$$

Figure 1(b) describes the pattern in one cycle of male transfer for $m=4$.

In the HAN-rotational system, the male transfer system is different according to whether the number of groups $(m)$ is even or odd. With an even value of $m, t_{\mathrm{c}}$ and $d(i, t)$ are given as

and

$$
t_{\mathrm{c}}=\operatorname{CEIL}\left(\log _{2} m\right),
$$

$$
d(i, t)= \begin{cases}i+2^{t-1} & \text { for } i+2^{t-1} \leqslant m \\ i+2^{t-1}-m & \text { for } i+2^{t-1}>m,\end{cases}
$$

where CEIL $\left(\log _{2} m\right)$ is the smallest integer greater than or equal to $\log _{2} m$. When the number of groups is odd, $t_{\mathrm{c}}$ is obtained as the smallest integer which makes $\left(2^{t_{c}}-1\right) / m$ equal to an integer, eg, $t_{\mathrm{c}}=4$ for $m=5$. The function $d(i, t)$ for odd values of $m$ is given as

$$
d(i, t)= \begin{cases}i+\operatorname{MOD}\left(2^{t-1}, m\right) & \text { for } i+\operatorname{MOD}\left(2^{t-1}, m\right) \leqslant m \\ i+\operatorname{MOD}\left(2^{t-1}, m\right)-m & \text { for } i+\operatorname{MOD}\left(2^{t-1}, m\right)>m,\end{cases}
$$

where $\operatorname{MOD}\left(2^{t-1}, m\right)$ is the remainder of $2^{t-1}$ divided by $m$. Figure $1(\mathrm{c})$ and (d) illustrate one cycle of the male transfer, for $m=4$ and 5 respectively.

A series of Cockerham's system is defined depending on the length of cycle $t_{\mathrm{c}}=1,2, \ldots$, TRUNC $\left(\log _{2} m\right)$, where TRUNC $\left(\log _{2} m\right)$ is the largest integer which is smaller than or equal to $\log _{2} m$. In this series, the function $d(i, t)$ is defined as

$$
d(i, t)= \begin{cases}i+2^{t-1} & \text { for } i+2^{t-1} \leqslant m \\ i+2^{t-1}-m & \text { for } i+2^{t-1}>m .\end{cases}
$$

In an extreme case of $t_{\mathrm{c}}=1$, the male transfer follows the same pattern as in circular group mating. The system with the maximum length of cycle, ie, $t_{\mathrm{c}}=$ TRUNC $\left(\log _{2} m\right)$, is investigated in this study. Under this system, genes of mated individuals have no common ancestral groups in $t_{c}$ preceding generations (Cockerham, 1970). When $m$ is an integral power of 2, Cockerham's system is identical to the HAN-rotational system. The pattern with $m=5$ is illustrated in figure 1(e). For comprehension, male transfers from group 1 , ie, the values of $d(1, t)$ in the three cyclical systems, are presented in table I for $m=4-20$.

The inbreeding coefficient and the inbreeding effective population size for circular group mating are computed by the method of Kimura and Crow (1963). With appropriate modifications as described in the Appendix, this method can be applied to the other systems. 
(a) Circular Group mating; $m=4$

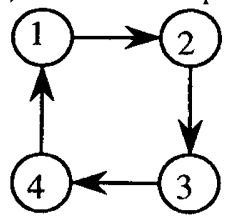

all generations

(b) Falconer's cyclical system; $m=4, t_{c}=3$

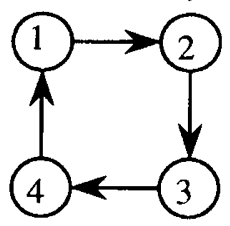

$\mathrm{t}=1,4,7, \ldots$

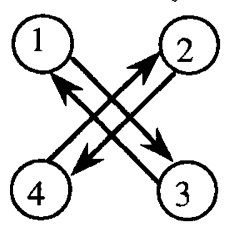

$2,5,8, \ldots$

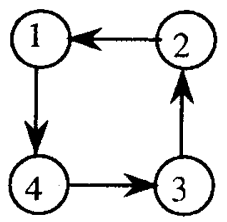

$3,6,9, \ldots$

(c) HAN-rotational system; $m=4, t_{c}=2$

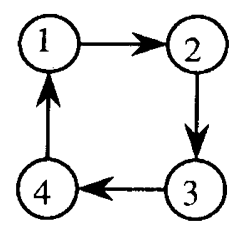

$\mathrm{t}=1,3,5, \ldots$

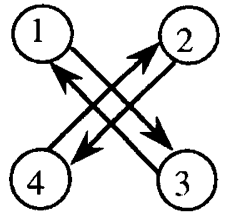

$2,4,6, \ldots$

(d) HAN-rotational system; $m=5, t_{c}=4$

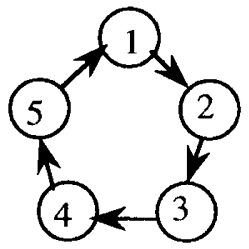

$\mathrm{t}=1,5,9, \ldots$

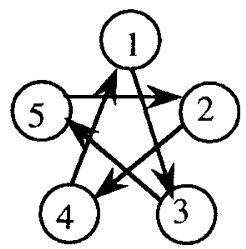

$2,6,10, \ldots$

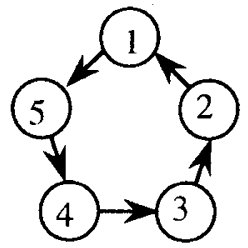

$3,7,11, \ldots$

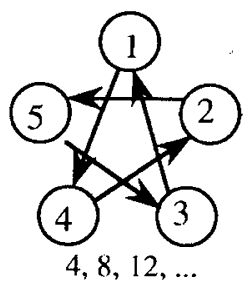

(e) Cockerham's cyclical system; $m=5, t_{c}=2$

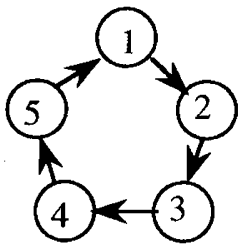

$\mathrm{t}=1,3,5, \ldots$

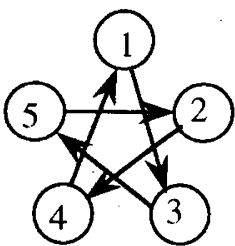

$2,4,6, \ldots$

Fig 1. Illustration of the four mating systems investigated. The arrows show the direction of male transfer. $m=$ number of groups; $t_{\mathrm{c}}=$ length of cycle. 
Table I. Design of male transfer in the three cyclical systems investigated. The values of $d(1, t)$, ie, the group to which males in group 1 are transferred, are listed for group numbers 4 to 20 .

\begin{tabular}{|c|c|c|c|c|c|c|c|c|c|c|c|c|c|c|c|c|c|c|c|c|c|}
\hline \multirow[b]{2}{*}{$\begin{array}{l}\text { Mating } \\
\text { system }\end{array}$} & \multirow[b]{2}{*}{$\begin{array}{l}\text { No of } \\
\text { groups }\end{array}$} & \multicolumn{20}{|c|}{ Generation within cycle $(\mathrm{t})$} \\
\hline & & 1 & 23 & 34 & & 5 & 6 & 7 & 8 & 9 & 10 & 11 & 12 & 13 & 14 & 15 & 16 & 6 & 17 & 18 & 19 \\
\hline Falconer & $\begin{array}{r}4 \\
5 \\
6 \\
7 \\
8 \\
9 \\
10 \\
11 \\
12 \\
13 \\
14 \\
15 \\
16 \\
17 \\
18 \\
19 \\
20\end{array}$ & $\begin{array}{l}2 \\
2 \\
2 \\
2 \\
2 \\
2 \\
2 \\
2 \\
2 \\
2 \\
2 \\
2 \\
2 \\
2 \\
2 \\
2 \\
2\end{array}$ & $\begin{array}{ll}3 & 4 \\
3 & 4 \\
3 & 4 \\
3 & 4 \\
3 & 4 \\
3 & 4 \\
3 & 4 \\
3 & 4 \\
3 & 4 \\
3 & 4 \\
3 & 4 \\
3 & 4 \\
3 & 4 \\
3 & 4 \\
3 & 4 \\
3 & 4 \\
3 & 4\end{array}$ & $\begin{array}{ll}4 & \\
4 & 5 \\
4 & 5 \\
4 & 5 \\
4 & 5 \\
4 & 5 \\
4 & 5 \\
4 & 5 \\
4 & 5 \\
4 & 5 \\
4 & 5 \\
4 & 5 \\
4 & 5 \\
4 & 5 \\
4 & 5 \\
4 & 5 \\
4 & 5\end{array}$ & & $\begin{array}{l}6 \\
6 \\
6 \\
6 \\
6 \\
6 \\
6 \\
6 \\
6 \\
6 \\
6 \\
6 \\
6 \\
6 \\
6\end{array}$ & $\begin{array}{l}7 \\
7 \\
7 \\
7 \\
7 \\
7 \\
7 \\
7 \\
7 \\
7 \\
7 \\
7 \\
7 \\
7\end{array}$ & $\begin{array}{l}8 \\
8 \\
8 \\
8 \\
8 \\
8 \\
8 \\
8 \\
8 \\
8 \\
8 \\
8 \\
8\end{array}$ & $\begin{array}{l}9 \\
9 \\
9 \\
9 \\
9 \\
9 \\
9 \\
9 \\
9 \\
9 \\
9 \\
9\end{array}$ & $\begin{array}{l}10 \\
10 \\
10 \\
10 \\
10 \\
10 \\
10 \\
10 \\
10 \\
10 \\
10\end{array}$ & $\begin{array}{l}11 \\
11 \\
11 \\
11 \\
11 \\
11 \\
11 \\
11 \\
11 \\
11\end{array}$ & $\begin{array}{l}12 \\
12 \\
12 \\
12 \\
12 \\
12 \\
12 \\
12 \\
12\end{array}$ & $\begin{array}{l}13 \\
13 \\
13 \\
13 \\
13 \\
13 \\
13 \\
13\end{array}$ & $\begin{array}{l}14 \\
14 \\
14 \\
14 \\
14 \\
14 \\
14\end{array}$ & $\begin{array}{l}15 \\
15 \\
15 \\
15 \\
15 \\
15\end{array}$ & $\begin{array}{l}16 \\
16 \\
16 \\
16 \\
16\end{array}$ & $\begin{array}{l}17 \\
17 \\
17 \\
17\end{array}$ & $\begin{array}{ll}7 & \\
7 & 1 \\
7 & 1 \\
7 & 1\end{array}$ & $\begin{array}{l}18 \\
18 \\
18\end{array}$ & $\begin{array}{l}19 \\
19\end{array}$ & \\
\hline HAN & $\begin{array}{r}4 \\
5 \\
6 \\
7 \\
8 \\
9 \\
10 \\
11 \\
12 \\
13 \\
14 \\
15 \\
16 \\
17 \\
18 \\
19 \\
20\end{array}$ & $\begin{array}{l}2 \\
2 \\
2 \\
2 \\
2 \\
2 \\
2 \\
2 \\
2 \\
2 \\
2 \\
2 \\
2 \\
2 \\
2 \\
2 \\
2\end{array}$ & $\begin{array}{ll}3 & \\
3 & 5 \\
3 & 5 \\
3 & 5 \\
3 & 5 \\
3 & 5 \\
3 & 5 \\
3 & 5 \\
3 & 5 \\
3 & 5 \\
3 & 5 \\
3 & 5 \\
3 & 5 \\
3 & 5 \\
3 & 5 \\
3 & 5 \\
3 & 5\end{array}$ & $\begin{array}{ll}5 & 4 \\
5 & \\
5 & \\
5 & \\
5 & 9 \\
5 & 9 \\
5 & 9 \\
5 & 9 \\
5 & 9 \\
5 & 9 \\
5 & 9 \\
5 & 9 \\
5 & 9 \\
5 & 9 \\
5 & 9 \\
5 & 9\end{array}$ & $\begin{array}{l}1 \\
1 \\
1 \\
1\end{array}$ & $\begin{array}{l}7 \\
7 \\
7 \\
7\end{array}$ & $\begin{array}{l}16 \\
14\end{array}$ & $\begin{array}{r}14 \\
8\end{array}$ & $\begin{array}{l}10 \\
15\end{array}$ & 10 & 19 & 18 & 16 & 12 & 4 & 7 & 13 & & 6 & 11 & \\
\hline Cockerham & $\begin{array}{r}4 \\
5 \\
6 \\
7 \\
8 \\
9 \\
10 \\
11 \\
12 \\
13 \\
14 \\
15 \\
16 \\
17 \\
18 \\
19 \\
20\end{array}$ & $\begin{array}{l}2 \\
2 \\
2 \\
2 \\
2 \\
2 \\
2 \\
2 \\
2 \\
2 \\
2 \\
2 \\
2 \\
2 \\
2 \\
2 \\
2\end{array}$ & $\begin{array}{ll}3 & \\
3 & \\
3 & \\
3 & \\
3 & 5 \\
3 & 5 \\
3 & 5 \\
3 & 5 \\
3 & 5 \\
3 & 5 \\
3 & 5 \\
3 & 5 \\
3 & 5 \\
3 & 5 \\
3 & 5 \\
3 & 5 \\
3 & 5\end{array}$ & 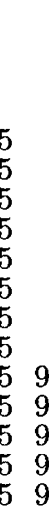 & & & & & & & & & & & & & & & & & \\
\hline
\end{tabular}




\section{NUMERICAL COMPUTATIONS}

In contrast with the progress of inbreeding in circular group mating, where males are transferred from the same neighbouring groups each generation, the inbreeding in a cyclical system is expected to increase in an oscillating pattern, since the relatedness of any two mated groups differs with generations. The oscillation pattern has been confirmed by Beilharz (1982) for a mouse population maintained by Falconer's system with each group being composed of one pair of parents. The oscillation was studied theoretically by Farid et al (1987). To evaluate the advantage of the cyclical systems, not only the average rate (trend) of inbreeding per generation but also the amplitude of oscillation should be taken into account.

Numerical computations revealed that, in all of the cyclical systems, the rates of inbreeding in generations within a cycle of male transfer $\left(\Delta F_{t^{\prime}} ; t^{\prime}=1,2, \ldots, t_{\mathrm{c}}\right)$ converge to steady values of their own after the third or fourth cycle. The steady values in generations in the fifth cycle were obtained for the cases of 4 to 21 groups of size $N_{\mathrm{m}}=2$ and $N_{\mathrm{f}}=4$, and are presented in table II. The rates of inbreeding with different sizes of $N_{\mathrm{m}}$ and $N_{\mathrm{f}}$ (data not presented) showed the same oscillation pattern though with different amplitudes.

In Falconer's system, a large increase of inbreeding takes place in the first generation regardless of the number of groups $(m)$. When $m$ is odd (table II $(b)$ ), this large increase occurs also in the $(m+1) / 2$-th generation. The large positive values of $\Delta F_{t^{\prime}}$ are followed by large negative values, indicating that the inbreeding coefficient increases in a cyclically oscillating pattern of rise and fall. $\Delta F_{t^{\prime}}$ takes a large positive value in generations when males are transferred back to the groups from which their fathers came. In such generations, two individuals paired may have a common grandparent, so that the progenies produced are more highly inbred than those in the previous generation. This high inbreeding, however, is reduced immediately in the next generation, since females are mated with males from less related groups.

In HAN-rotational and Cockerham's systems, the pattern of $\Delta F_{t^{\prime}}$ varies with the number of groups. When $m$ is an integral power of 2 , the two systems show no oscillation in $\Delta F_{t^{\prime}}$ and give the same rate of inbreeding each generation. With other even numbers of $m$, the two systems show different patterns of $\Delta F_{t^{\prime}}$ : in the HAN-rotational system, $\Delta F_{t^{\prime}}$ starts with a negative value and ends with a positive value (table II(a)), whereas in Cockerham's system, $\Delta F_{t^{\prime}}$ takes positive values in all cases but that of $m=14$, indicating that the inbreeding coefficient increases steadily without oscillation. When $m$ is odd, the HAN-rotational system always gives a constant $\Delta F_{t^{\prime}}$. In Cockerham's system, $\Delta F_{t^{\prime}}$ is constant only when $m=5$, 9 and 17. In general, in Cockerham's system with $m=2^{n}+1,(n=1,2,3, \ldots)$, groups mated in any generation share $2^{n}-1$ common ancestral groups in the $n-1$ th previous generation, so that the relatedness among the groups mated, and therefore $\Delta F_{t^{\prime}}$, stays constant in all generations.

Figure 2 illustrates the increase of inbreeding coefficients in the initial 30 generations under the four group mating systems with numbers of groups varying from 4 to 15 . Inbreeding in an undivided randomly-mating population of a 


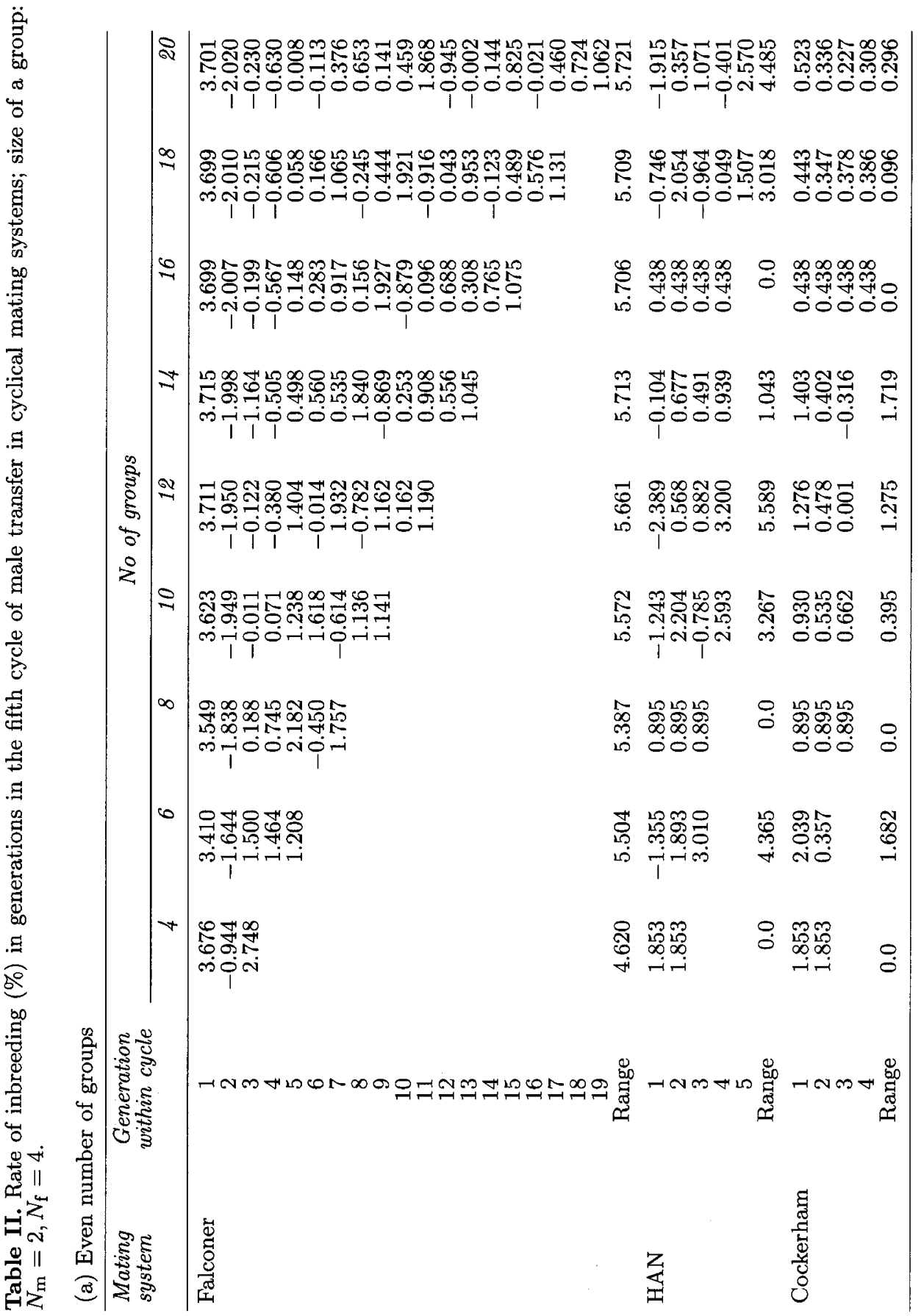




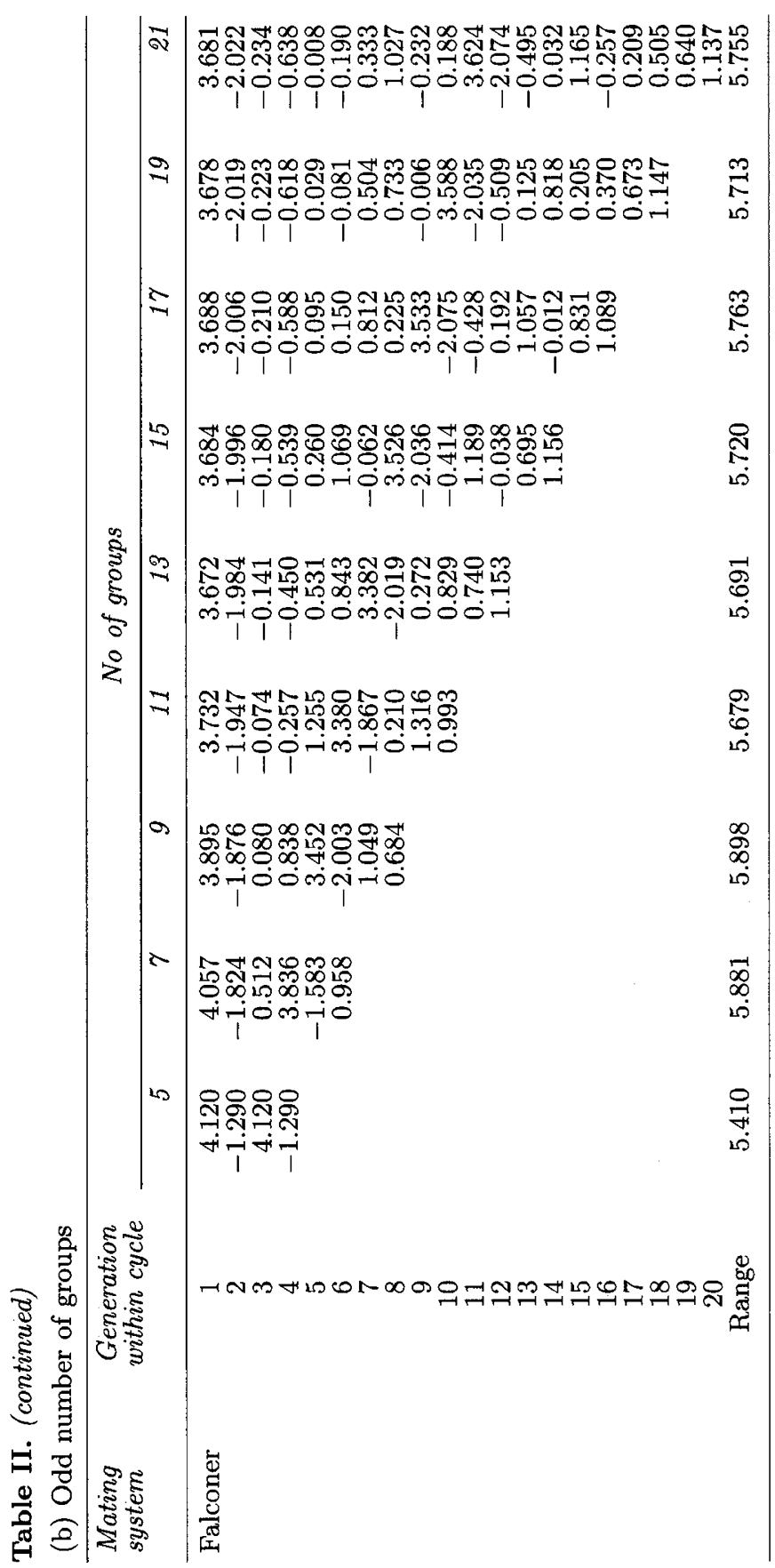




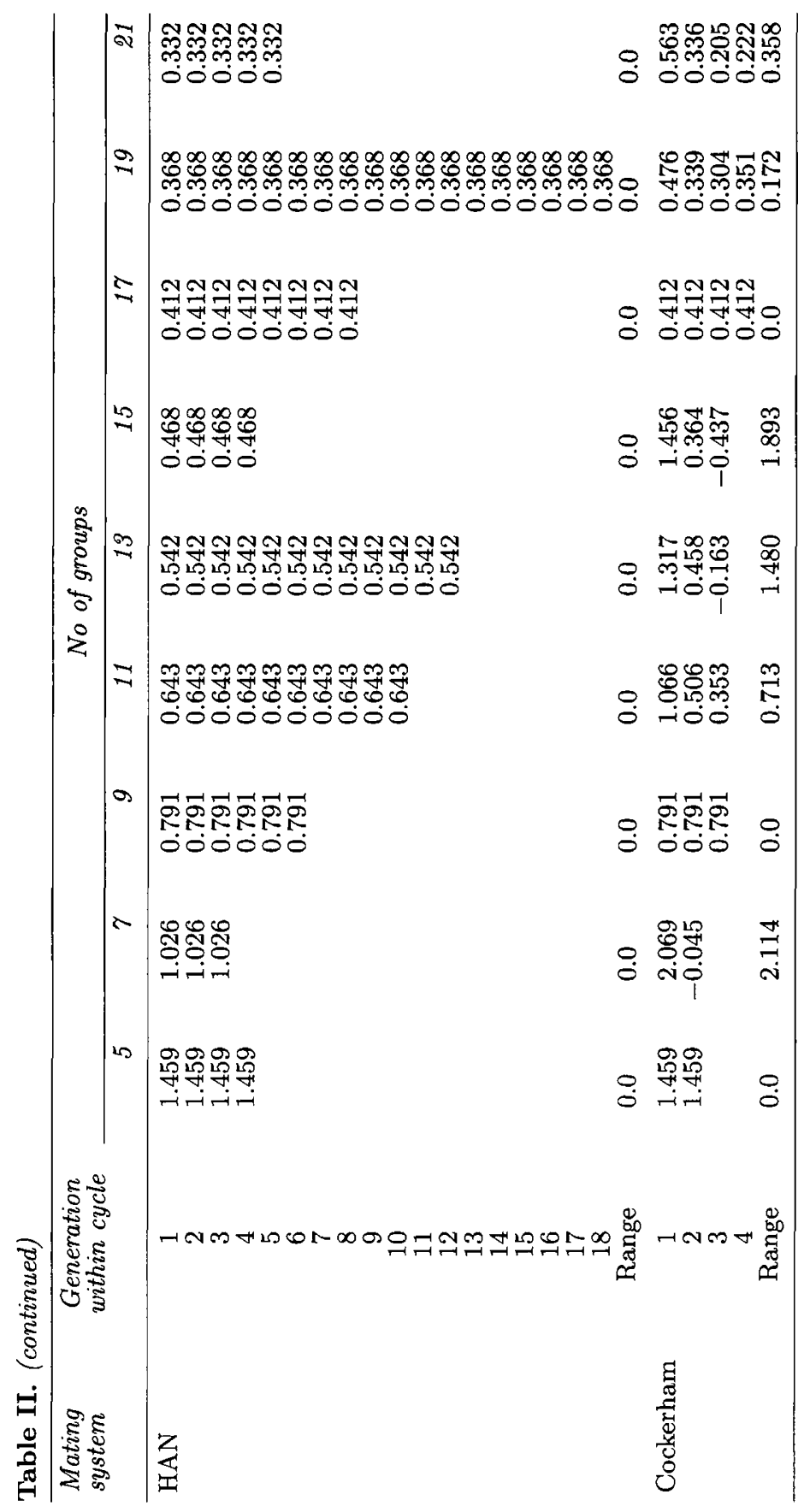


size $N_{\mathrm{M}}+N_{\mathrm{F}}$ was added as a check, being computed by Wright's formula (Wright, 1931),

$$
F_{t}=F_{t-1}+\frac{1}{2 N_{\mathrm{E}(\mathrm{RM})}}\left(1-2 F_{t-1}+F_{t-2}\right),
$$

where $N_{\mathrm{E}(\mathrm{RM})}$ is the effective population size, $4 N_{\mathrm{M}} N_{\mathrm{F}} /\left(N_{\mathrm{M}}+N_{\mathrm{F}}\right)$.

When the number of groups $m$ is 4 or 5 , there are only small differences between the four systems for any total population size. In circular group mating an increase

(a) Even number of groups
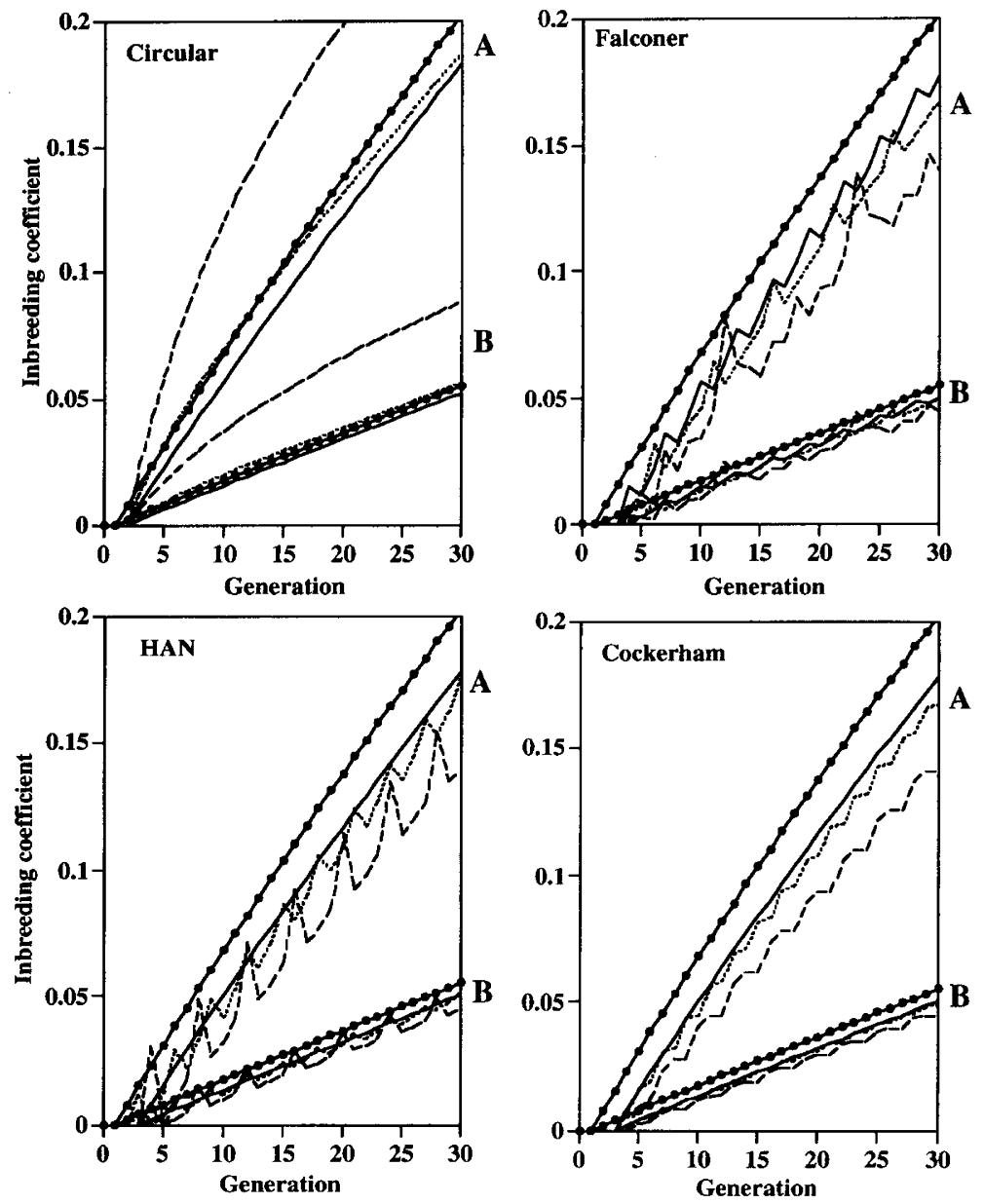

$\longrightarrow$ : random mating
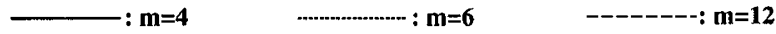
(b) Odd number of groups
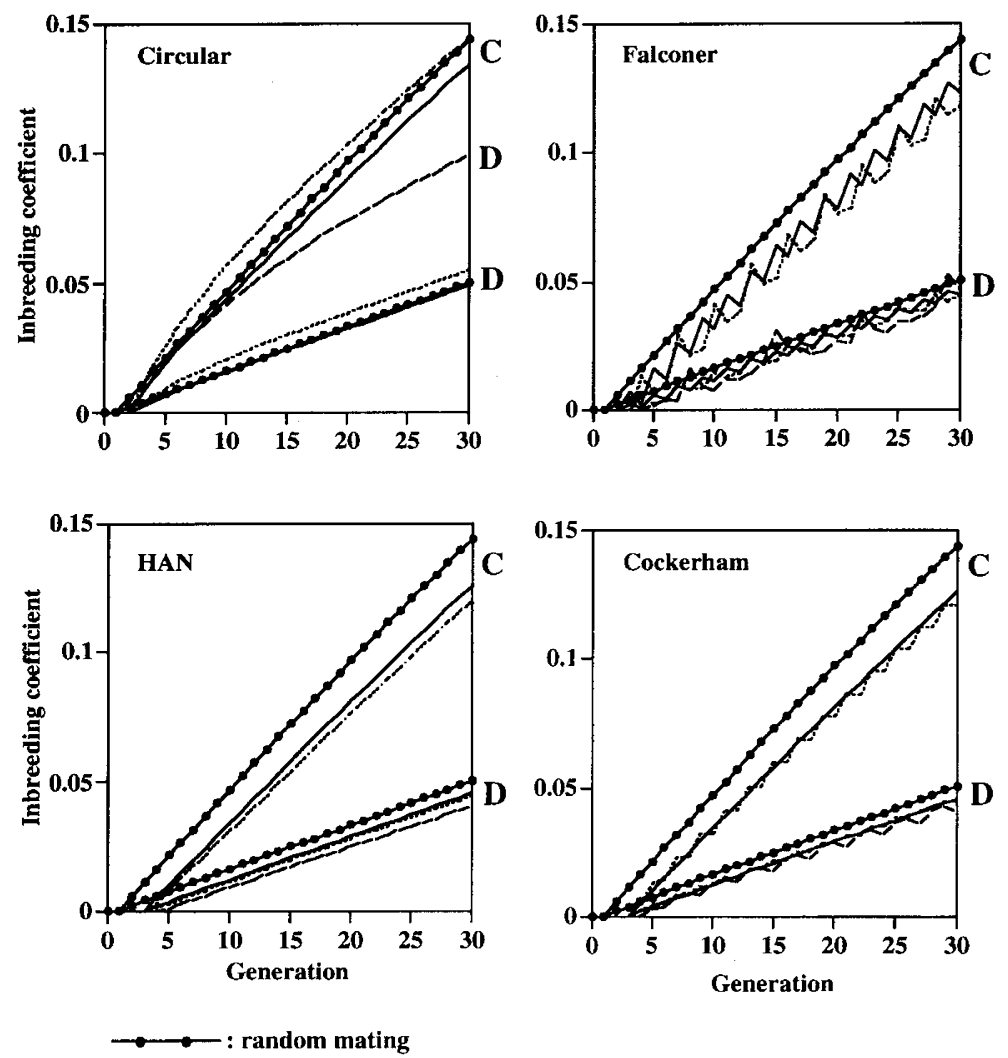

$: \mathbf{m}=\mathbf{5}$ : $\mathbf{m}=\mathbf{7}$

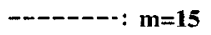

Fig 2. Inbreeding coefficients in the initial 30 generations under the four systems of group mating. For even numbers of groups: A: $N_{\mathrm{M}}=24, N_{\mathrm{F}}=48$ (corresponding to $\left.N_{\mathrm{E}(\mathrm{RM})}=64\right) ; \mathrm{B}: N_{\mathrm{M}}=96, N_{\mathrm{F}}=192$ (corresponding to $N_{\mathrm{E}(\mathrm{RM})}=256$ ). For odd numbers of groups: C: $N_{\mathrm{M}}=35, N_{\mathrm{F}}=70$ (corresponding to $N_{\mathrm{E}(\mathrm{RM})}=93.33$ ); D: $N_{\mathrm{M}}=105, N_{\mathrm{F}}=210$ (corresponding to $N_{\mathrm{E}(\mathrm{RM})}=280$ ).

in $m$ leads to increased inbreeding. When $m$ is larger than 6 , the inbreeding coefficient in circular group mating surpasses that in random mating. The inflation of inbreeding is ascribed to an increased occurrence of single cousin mating. In circular group mating, females in a group are mated with males coming from the same group in all generations, and so single cousin mating occurs with a probability of

$$
\frac{N_{\mathrm{m}}+N_{\mathrm{f}}-1}{N_{\mathrm{m}} N_{\mathrm{f}}}=\frac{m\left(N_{\mathrm{M}}+N_{\mathrm{F}}\right)-m^{2}}{N_{\mathrm{M}} N_{\mathrm{F}}} .
$$

Since $N_{\mathrm{m}}$ and $N_{\mathrm{F}}$ are both $\geqslant m$, this probability is an increasing function of $m$. 
For the same reason, the oscillation amplitude of inbreeding under cyclical systems is enhanced with an increase in the number of groups. However, except in some generations when the inbreeding increases sharply, the inbreeding coefficients are smaller than those with random mating. This superiority of cyclical systems over random mating increases with increasing number of groups, though the difference is fairly trivial when the total population size is large.

Table III. Inbreeding effective population size under random and group mating.

\begin{tabular}{|c|c|c|c|c|c|c|c|c|c|}
\hline \multirow[b]{2}{*}{ Case } & \multirow[b]{2}{*}{$\mathrm{N}_{M}$} & \multirow[b]{2}{*}{$\mathrm{N}_{F}$} & \multirow[b]{2}{*}{$\mathrm{N}$} & \multirow{2}{*}{$\begin{array}{c}\text { Random } \\
\text { mating } \\
\mathrm{N}_{E(R M)}\end{array}$} & \multicolumn{5}{|c|}{ Group mating } \\
\hline & & & & & $\mathrm{m}$ & Circular & Falconer & $H A N$ & Cockerham \\
\hline 1 & 24 & 48 & 72 & 64.00 & $\begin{array}{r}4 \\
6 \\
8 \\
12\end{array}$ & $\begin{array}{c}70.08 \\
75.53 \\
82.44 \\
100.83\end{array}$ & $\begin{array}{l}69.64 \\
73.56 \\
77.45 \\
85.55\end{array}$ & $\begin{array}{l}69.56 \\
73.58 \\
77.14 \\
85.46\end{array}$ & $\begin{array}{l}69.53 \\
73.54 \\
77.14 \\
85.27\end{array}$ \\
\hline 2 & 35 & 70 & 105 & 93.33 & $\begin{array}{l}5 \\
7\end{array}$ & $\begin{array}{l}101.92 \\
108.05\end{array}$ & $\begin{array}{l}100.98 \\
104.91\end{array}$ & $\begin{array}{l}100.82 \\
104.62\end{array}$ & $\begin{array}{l}100.82 \\
105.00\end{array}$ \\
\hline 3 & 48 & 96 & 144 & 128.00 & $\begin{array}{r}4 \\
6 \\
8 \\
12 \\
16\end{array}$ & $\begin{array}{l}134.04 \\
139.44 \\
146.25 \\
164.23 \\
188.31\end{array}$ & $\begin{array}{l}133.61 \\
137.51 \\
141.39 \\
149.45 \\
157,49\end{array}$ & $\begin{array}{l}133.53 \\
137.53 \\
141.07 \\
149.37 \\
156.66\end{array}$ & $\begin{array}{l}133.53 \\
137.49 \\
141.07 \\
149.17 \\
156.66\end{array}$ \\
\hline 4 & 96 & 192 & 288 & 256.00 & $\begin{array}{r}4 \\
6 \\
8 \\
12 \\
16 \\
24 \\
32\end{array}$ & $\begin{array}{l}262.02 \\
267.39 \\
274.13 \\
291.83 \\
315.34 \\
380.81 \\
472.13\end{array}$ & $\begin{array}{l}261.60 \\
265.48 \\
269.35 \\
277.39 \\
285.41 \\
301.77 \\
318.12\end{array}$ & $\begin{array}{l}261.52 \\
265.02 \\
269.04 \\
277.31 \\
284.59 \\
301.56 \\
316.17\end{array}$ & $\begin{array}{l}261.52 \\
265.02 \\
269.04 \\
277.11 \\
284.59 \\
300.82 \\
316.17\end{array}$ \\
\hline 5 & 105 & 210 & 315 & 280.00 & $\begin{array}{r}5 \\
7 \\
15 \\
35\end{array}$ & $\begin{array}{l}288.53 \\
294.58 \\
332.82 \\
536.34\end{array}$ & $\begin{array}{l}287.61 \\
291.51 \\
307.59 \\
348.42\end{array}$ & $\begin{array}{l}287.45 \\
291.23 \\
306.69 \\
346.16\end{array}$ & $\begin{array}{l}287.45 \\
291.61 \\
307.61 \\
346.16\end{array}$ \\
\hline 6 & 192 & 384 & 576 & 512.00 & $\begin{array}{r}4 \\
6 \\
8 \\
12 \\
16 \\
24 \\
32\end{array}$ & $\begin{array}{l}518.01 \\
523.36 \\
530.07 \\
547.59 \\
570.73 \\
634.52 \\
722.87\end{array}$ & $\begin{array}{l}517.59 \\
521.47 \\
525.33 \\
533.36 \\
541.36 \\
557.70 \\
574.03\end{array}$ & $\begin{array}{l}517.51 \\
521.49 \\
521.02 \\
533.28 \\
540.55 \\
557.29 \\
572.10\end{array}$ & $\begin{array}{l}517.51 \\
521.44 \\
521.02 \\
533.08 \\
540.55 \\
556.75 \\
572.10\end{array}$ \\
\hline
\end{tabular}

Table III presents the effective population size for random and four group mating systems. (Average effective size $\bar{N}_{\mathrm{E}}$, defined in the Appendix, is presented for cyclical systems). These effective population sizes are asymptotic ones and determine the progress of inbreeding after sufficiently many generations. The effective population sizes in the four group mating systems are always greater than that of random mating. In all group mating systems an increase in $m$ results in an increased effective population size. With a given number of groups and total population size, the effective population size in circular group mating is larger than 
those in the three cyclical systems, meaning that the inbreeding under circular group mating will eventually become smaller, although it is larger in early generations (cf fig 2), than under the cyclical systems.

The critical generations in which the inbreeding coefficients in circular and cyclical mating reverse in rank, together with the inbreeding value per se in these generations, are presented in table IV. The critical generations depend largely on the total population size; the reversal occurs at later generations with larger populations sizes. The values of inbreeding in this turning-point generation, however, do not differ much from each other, ie, the inbreeding coefficient lies within the range of $60-73 \%$ over all of the group numbers and total population sizes calculated. Calculations of the inbreeding coefficients after this critical generation (data not presented) showed that the superiority of circular mating over cyclical matings is rather trivial, ie, less than $2 \%$ in all of the cases studied (4-35 groups and 300-2000 generations).

Table IV. Generation $(t)$ in which circular mating first gives lower inbreeding than cyclical systems, and the inbreeding coefficient $\left(F_{t}\right)$ of circular mating in that generation.

\begin{tabular}{|c|c|c|c|c|c|c|c|}
\hline \multirow[b]{2}{*}{ Case $^{\mathrm{a}}$} & \multirow[b]{2}{*}{$\mathrm{m}$} & \multicolumn{2}{|c|}{ Falconer } & \multicolumn{2}{|c|}{$H A N$} & \multicolumn{2}{|c|}{ Cockerham } \\
\hline & & $\mathrm{t}$ & $\mathrm{F}_{\mathrm{t}}(\%)$ & $\mathrm{t}$ & $\mathrm{F}_{\mathrm{t}}(\%)$ & $\mathrm{t}$ & $\overline{F_{t}(\%)}$ \\
\hline 1 & $\begin{array}{r}4 \\
6 \\
8 \\
12\end{array}$ & $\begin{array}{l}171 \\
164 \\
175 \\
199\end{array}$ & $\begin{array}{l}70.22 \\
66.12 \\
67.04 \\
68.28\end{array}$ & $\begin{array}{l}142 \\
167 \\
166 \\
207\end{array}$ & $\begin{array}{l}63.34 \\
67.28 \\
65.19 \\
69.52\end{array}$ & $\begin{array}{l}142 \\
141 \\
166 \\
196\end{array}$ & $\begin{array}{l}63.34 \\
61.10 \\
65.19 \\
67.81\end{array}$ \\
\hline 2 & $\begin{array}{l}5 \\
7\end{array}$ & $\begin{array}{l}307 \\
250\end{array}$ & $\begin{array}{l}77.82 \\
69.16\end{array}$ & $\begin{array}{l}206 \\
218\end{array}$ & $\begin{array}{l}63.55 \\
64.23\end{array}$ & $\begin{array}{l}206 \\
201\end{array}$ & $\begin{array}{l}63.55 \\
61.29\end{array}$ \\
\hline 3 & $\begin{array}{r}4 \\
6 \\
8 \\
12 \\
16\end{array}$ & $\begin{array}{l}324 \\
299 \\
301 \\
330 \\
361\end{array}$ & $\begin{array}{l}69.99 \\
65.95 \\
65.15 \\
66.53 \\
68.02\end{array}$ & $\begin{array}{l}270 \\
305 \\
294 \\
339 \\
363\end{array}$ & $\begin{array}{l}63.28 \\
66.68 \\
64.31 \\
67.43 \\
68.19\end{array}$ & $\begin{array}{l}270 \\
257 \\
294 \\
322 \\
363\end{array}$ & $\begin{array}{l}63.28 \\
60.41 \\
64.31 \\
65.70 \\
68.19\end{array}$ \\
\hline 4 & $\begin{array}{r}4 \\
6 \\
8 \\
12 \\
16 \\
24 \\
32\end{array}$ & $\begin{array}{l}630 \\
574 \\
560 \\
594 \\
616 \\
713 \\
807\end{array}$ & $\begin{array}{l}69.87 \\
65.90 \\
64.44 \\
65.52 \\
65.88 \\
69.26 \\
72.16\end{array}$ & $\begin{array}{l}526 \\
584 \\
550 \\
603 \\
621 \\
727 \\
827\end{array}$ & $\begin{array}{l}63.25 \\
65.53 \\
63.79 \\
66.05 \\
66.15 \\
69.82 \\
72.74\end{array}$ & $\begin{array}{l}526 \\
491 \\
550 \\
574 \\
621 \\
714 \\
827\end{array}$ & $\begin{array}{l}63.25 \\
60.17 \\
63.79 \\
64.32 \\
66.15 \\
69.30 \\
72.74\end{array}$ \\
\hline 5 & $\begin{array}{r}5 \\
7 \\
15 \\
35\end{array}$ & $\begin{array}{l}875 \\
682 \\
659 \\
912\end{array}$ & $\begin{array}{l}78.04 \\
68.78 \\
65.62 \\
73.32\end{array}$ & $\begin{array}{l}580 \\
592 \\
659 \\
923\end{array}$ & $\begin{array}{l}63.37 \\
63.62 \\
65.62 \\
73.44\end{array}$ & $\begin{array}{l}580 \\
543 \\
652 \\
923\end{array}$ & $\begin{array}{l}63.37 \\
60.46 \\
65.25 \\
73.44\end{array}$ \\
\hline 6 & $\begin{array}{r}4 \\
6 \\
8 \\
12 \\
16 \\
24 \\
32\end{array}$ & $\begin{array}{l}1245 \\
1119 \\
1078 \\
1100 \\
1111 \\
1197 \\
1334\end{array}$ & $\begin{array}{l}69.89 \\
65.71 \\
64.06 \\
64.24 \\
64.11 \\
65.88 \\
68.79\end{array}$ & $\begin{array}{l}1038 \\
1139 \\
1062 \\
1131 \\
1133 \\
1249 \\
1352\end{array}$ & $\begin{array}{l}63.23 \\
66.36 \\
62.51 \\
65.24 \\
64.79 \\
67.25 \\
69.18\end{array}$ & $\begin{array}{c}1038 \\
955 \\
1062 \\
1078 \\
1133 \\
1229 \\
1352\end{array}$ & $\begin{array}{l}63.23 \\
59.89 \\
63.51 \\
63.52 \\
64.79 \\
66.73 \\
69.18\end{array}$ \\
\hline
\end{tabular}

${ }^{a}$ As in Table III. 


\section{DISCUSSION}

Kimura and Crow (1963) studied three types of circular mating, ie, circular individual, circular pair, and circular group mating, and concluded that the effective population size of the three circular mating systems is larger than that of random mating. Robertson (1964) obtained a more generalized conclusion, saying that not only the circular mating systems as studied by Kimura and Crow (1963), but any other types of population subdivision, like the cyclical systems discussed in this paper, enlarge the effective population size.

Superiority of group matings over random mating is rather small, however, unless the total population size is small. It is shown in figure 2 that when $N_{\mathrm{E}}$ is as large as 250 , a population may be maintained either in one location as one population or in separate groups (by cyclical mating). In many conservation programmes, the number of animals maintainable in one location is severely restricted due to the limited facilities. In such cases the population must be maintained in a number of small groups located in different stations such as zoological gardens and natural parks. As Yamada (1980) suggested, group mating should be used in this situation, since it is not only effective in suppressing the progress of inbreeding but also much easier to practise than random mating of the whole population (Rochambeau and Chevalet, 1990). Maintenance in different locations has the additional merit of reducing the risk of accidental loss of the population.

In the numerical computations presented in figure 2 and tables III and IV, the best system of group mating changes with duration (generations) of population maintenance. The cyclical systems would be recommended for short- or intermediate-term maintenance, ie, a few hundreds or fewer generations as far as a population with an effective size of about 100 is concerned. The advantage of the cyclical systems is more prominent when the population is partitioned into more groups. For long-term conservation, on the other hand, circular group mating appears superior, though only slightly, to the cyclical systems (tables III and IV). Application of circular group mating is rather limited, however. The superiority of circular group mating is attained only after some generations where the inbreeding coefficient has already exceeded the critical level of inbreeding $(50-60 \%)$ for survival of animal populations (Soulé, 1980). When, as is the case in many practical projects, the population is initiated from relatively highly related animals, its survival will be determined by the progress of inbreeding in early generations. To avoid extinction due to inbreeding depression in early generations, cyclical systems should be preferred. When pedigree information of the starting animals is available, the initial groups may be constructed with the minimum relatedness among groups, leading to a further reduction in the rate of inbreeding in initial generations (Rochambeau and Chevalet, 1982).

Inbreeding proceeds in any population of a limited size. This does not necessarily mean that the population will eventually become extinct by inbreeding depression. Inbreeding, if it proceeds gradually, may not cause serious inbreeding depression, because deleterious alleles can be eliminated gradually through selection. The slower the progress of inbreeding, the greater the opportunity for the deleterious alleles to be eliminated (Lande and Barowclough, 1987). In this respect also, cyclical group mating is superior to circular mating. 
It is concluded that cyclical systems have much wider application than circular group mating. Of the three cyclical systems examined, the one which exhibits the least oscillating pattern of inbreeding should be chosen. A sharp increase in inbreeding in one generation may cause a serious inbreeding depression, as evidenced in the experiment of Beilharz (1982) using a mouse population. As seen in table II, the best system differs with the number of groups $(m)$ : with an odd number of groups the HAN-rotational system is recommended, while Cockerham's system is advisable for an even number.

The number of groups is a key factor determining the result of a conservation programme (Rochambeau and Chevalet, 1982). As indicated in figure 2, a large number of groups is more favourable. The number of groups, however, cannot be large when the total number of animals is limited; each group must be sufficiently large to ensure its persistence. Optimal allocation of the animals must be chosen, taking account not only of the genetic factor as discussed in this paper but also demographic parameters like reproductive and survival rates.

Only inbreeding has been investigated in the present study. When conserving animals as genetic resources, the maintenance of genetic variability must also be taken into account. Theoretically, the largest genetic variability will be maintained when the population is split into a number of completely isolated groups, but on the other hand a high rate of inbreeding will be caused within the groups (Kimura and Crow, 1963; Robertson, 1964). To compromise between these two conflicting effects, not all but some appropriate proportion of males or females may be exchanged among groups. The mating system proposed by Alderson (1990b) is one possible system to cope with this problem. In his system, a proportion of females in each group are transferred to a neighbouring group in the same pattern as in the circular mating, the remaining females being mated to males of the same group. The effectiveness of systems with partial transfer of males or females is another problem to be addressed, and will be thoroughly discussed elsewhere.

\section{REFERENCES}

Alderson L (1990a) The work of the rare breeds survival trust. In: Genetic Conservation of Domestic Livestock (L Alderson, ed), CAB International, Wallingford, 32-44

Alderson L (1990b) The relevance of genetic improvement programmes within a policy for genetic conservation. In: Genetic Conservation of Domestic Livestock (L Alderson, ed), CAB International, Wallingford, 206-220

Alderson L (1992) A system to maximize the maintenance of genetic variability in small populations. In: Genetic Conservation of Domestic Livestock (L Alderson, I Bodo, eds), Vol 2, CAB International, Wallingford, 18-29

Beilharz RG (1982) The effect of inbreeding on reproduction in mice. Anim Prod 34, 49-54

Bodo I (1990) The maintenance of Hungarian breeds of farm animals threatened by extinction. In: Genetic Conservation of Domestic Livestock (L Alderson, ed), CAB International, Wallingford, 73-84

Cockerham CC (1970) Avoidance and rate of inbreeding. In: Mathematical Topics in Population Genetics (K Kojima, ed), Springer, New York, 104-127

Eggenberger Von E (1973) Modellpopulationen zur Beurteilung von Rotationssystmen in der Versuchstierzucht. $Z$ Versuchstierk 15, 297-331 
Falconer DS (1967) Genetic aspects of breeding methods. In: The UFAW Handbook on the Care and Management of Laboratory Animals (W Lane-Petter, ed), 3rd edition, Livinstone, Edinburgh, 72-96

Farid A, Mararechian M, Stobeck C (1987) Inbreeding under a cyclical mating system. Theor Appl Genet 73, 506-515

Kimura M, Crow JF (1963) On the maximum avoidance of inbreeding. Genet Res Camb 4, 399-415

Lande R, Barrowclough GF (1987) Effective population size, genetic variation, and their use in population management. In: Viable Populations for Conservation (ME Soulé, ed), Cambridge University Press, Cambridge, 87-123

Maijala K, Cherekaev AV, Devillard JM, Reklewski Z, Rognoni G, Simon DL, Steane D (1984) Conservation of animal genetic resources in Europe. Final report of the European Association of Animal Production Working Party. Livest Prod Sci 11, 3-22

Matheron G, Chevalet C (1977) Design of a control line of rabbits: Expected evolution of individual inbreeding coefficients according to various mating schemes. Ann Génét Sél Anim 9, 1-13

Poiley SM (1960) A systematic method of breeder rotation for non-inbred laboratory animal colonies. Proc Anim Care Panel 10, 159-166

Rapp G (1972) HAN-rotation, a new system for rigorous outbreeding. $Z$ Versuchstierk 14, 133-142

Robertson A (1964) The effect of non-random mating within inbred lines on the rate of inbreeding. Genet Res Camb 5, 164-167

de Rochambeau H, Chevalet C (1982) Some aspects of the genetic management of small breeds. In: Proc 2nd World Cong Genet Appl Livest Prod, Madrid, VII, 282-287

de Rochambeau H, Chevalet C (1985) Minimisation des coefficients de consanguinité moyens dans les petites populations d'animaux domestiques. Genet Sel Evol 17, 459-480

de Rochambeau H, Chevalet C (1990) Genetic principles of conservation. In: Proc 4th World Cong Genet Appl Livest Prod, Edinburgh, XIV, 434-442

Soulé ME (1980) Thresholds for survival: maintaining fitness and evolutionary potential. In: Conservation Biology. An Evolutionary-Ecological Perspective (ME Soulé, BA Wilcox, eds), Sinauer Associates, Sunderland, 151-169

Wright S (1921) Systems of mating. Genetics 6, 111-178

Wright S (1931) Evolution in Mendelian populations. Genetics 16, 97-159

Yamada Y (1980) The importance of mating systems in the conservation of animal genetic resources. FAO Animal Production and Health Paper 24, 268-278

\section{APPENDIX}

Following Kimura and Crow (1963), we define the following quantities:

$F_{t}=$ the inbreeding coefficient at generation $t$,

$J_{t}(0)=$ the probability that two homologous genes of two newly born individuals within a group are identical by descent, subscript $t$ showing generation,

$J_{t}(k)=$ the probability that two homologous genes of two newly born individuals in two different groups of distance $k$ are identical by descent, $k$ being in the range 1 to $n=m / 2$ when $m$ is even, and 1 to $n=(m-1 / 2)$ when $m$ is odd.

Defining vector $\mathbf{h}_{t}$ as

$$
\mathbf{h}_{t}^{\prime}=\left[1-F_{t} 1-J_{t}(0) 1-J_{t}(1) \ldots 1-J_{t}(n)\right],
$$


a recurrence relation,

$$
\mathbf{h}_{t}=\mathbf{G h}_{t-1}
$$

holds for circular group mating, where $\mathbf{G}$ is the transition matrix. With the largest eigen value $(\lambda)$ of the matrix $\mathbf{G}$, the inbreeding effective population size $\left(N_{\mathbb{E}}\right)$ is computed by

$$
N_{\mathrm{E}}=1 / 2(1-\lambda) .
$$

For a cyclical system of group mating, the recurrence relation varies with generations, but the same set of relations is repeated with a cycle of $t_{\mathrm{c}}$ generations. Thus, we need $t_{\mathrm{c}}$ matrices, $\mathbf{G}_{1}, \mathbf{G}_{2}, \ldots, \mathbf{G}_{t_{\mathrm{c}}}$. With these matrices, the recurrence relation is generally written as

$$
\mathbf{h}_{t}=\mathbf{G}_{t^{\prime}} \mathbf{h}_{t-1},
$$

where subscript $t^{\prime}\left(=1,2, \ldots, t_{\mathrm{c}}\right)$ shows a generation a generation within the cycle, formulated as $t^{\prime}=\operatorname{MOD}\left(t-1, t_{\mathrm{c}}\right)+1$. The matrices $\mathbf{G}_{t^{\prime}}$ are obtained in a way similar to Kimura and Crow (1963). For example, the matrices for Cockerham's system with $m=6$ are formulated as

$$
\begin{aligned}
\mathbf{G}_{1} & =\left[\begin{array}{ccccc}
0 & 0 & 1 & 0 & 0 \\
1 / N_{\mathrm{e}} & 1 / 2-1 / N_{\mathrm{e}} & 1 / 2 & 0 & 0 \\
0 & 1 / 4 & 1 / 2 & 1 / 4 & 0 \\
0 & 0 & 1 / 4 & 1 / 2 & 1 / 4 \\
0 & 0 & 0 & 1 / 2 & 1 / 2
\end{array}\right] \\
\mathbf{G}_{2} & =\left[\begin{array}{ccccc}
0 & 0 & 0 & 1 & 0 \\
1 / N_{\mathrm{e}} & 1 / 2-1 / N_{\mathrm{e}} & 0 & 1 / 2 & 0 \\
0 & 0 & 3 / 4 & 0 & 1 / 4 \\
0 & 1 / 4 & 0 & 3 / 4 & 0 \\
0 & 0 & 1 / 2 & 0 & 1 / 2
\end{array}\right]
\end{aligned}
$$

Since the rate of inbreeding is determined only through the effective size of the group $N_{\mathrm{e}}=4 N_{\mathrm{m}} N_{\mathrm{f}} /\left(N_{\mathrm{m}}+N_{\mathrm{f}}\right)$, the sex ratio has no effect on the rate of inbreeding so long as $N_{\mathrm{e}}$ is constant.

In some cases as shown in table II, the rate of inbreeding per generation changes from generation to generation. However, the rate of inbreeding per cycle, ie, $\left(F_{t+t_{c}}-F_{t}\right) /\left(1-F_{t}\right)$, approaches an asymptotic value after sufficiently many cycles. Defining a matrix $\mathbf{G}_{\mathrm{c}}$ as

$$
\mathbf{G}_{\mathrm{c}}=\mathbf{G}_{1} \mathbf{G}_{2} \ldots \mathbf{G}_{t_{\mathrm{c}}}
$$

the asymptotic value $\left(\Delta F_{\mathrm{c}}\right)$ is obtained, with $\lambda_{\mathrm{c}}$ showing the largest eigen value of $\mathbf{G}_{\mathrm{c}}$ as

$$
\Delta F_{\mathrm{c}}=1-\lambda_{\mathrm{c}}
$$


Introducing $\Delta \bar{F}$ and $\Delta F_{t^{\prime}}$ as the average rate of inbreeding per generation and the rate of inbreeding at generation $t^{\prime}$ within a cycle, respectively, a relation

$$
\Delta F_{\mathbf{c}}=1-\prod_{t^{\prime}=1}^{t_{\mathrm{c}}}\left(1-\Delta F_{t^{\prime}}\right)=1-(1-\Delta \bar{F})^{t_{\mathrm{c}}}
$$

is formulated. From equations [2] and [3], $\Delta \bar{F}$ is obtained as

$$
\Delta \bar{F}=1-\lambda_{\mathrm{c}}^{1 / t_{\mathrm{c}}} .
$$

Thus, the average inbreeding effective size $\left(\bar{N}_{\mathrm{E}}\right)$ per generation is computed by

$$
\bar{N}_{\mathrm{E}}=1 / 2 \Delta \bar{F}=1 / 2\left(1-\lambda_{\mathrm{c}}^{1 / t_{\mathrm{c}}}\right) .
$$

